Wright State University

CORE Scholar

$1-1-1998$

\title{
Effect of High-Temperature Annealing on Electrical and Optical Properties of Undoped Semi-Insulating GaAs
}

\author{
Z-Q. Fang \\ D. C. Reynolds
}

David C. Look

Wright State University - Main Campus, david.look@wright.edu

N. G. Paraskevopoulos

T. E. Anderson

See next page for additional authors

Follow this and additional works at: https://corescholar.libraries.wright.edu/physics

Part of the Physics Commons

\section{Repository Citation}

Fang, Z., Reynolds, D. C., Look, D. C., Paraskevopoulos, N. G., Anderson, T. E., \& Jones, R. L. (1998). Effect of High-Temperature Annealing on Electrical and Optical Properties of Undoped Semi-Insulating GaAs. Journal of Applied Physics, 83 (1), 260-265.

https://corescholar.libraries.wright.edu/physics/138

This Article is brought to you for free and open access by the Physics at CORE Scholar. It has been accepted for inclusion in Physics Faculty Publications by an authorized administrator of CORE Scholar. For more information, please contact library-corescholar@wright.edu. 


\section{Authors}

Z-Q. Fang, D. C. Reynolds, David C. Look, N. G. Paraskevopoulos, T. E. Anderson, and R. L. Jones 


\title{
Effect of high-temperature annealing on electrical and optical properties of undoped semi-insulating GaAs
}

\author{
Z.-Q. Fang, D. C. Reynolds, and D. C. Look \\ University Research Center and Physics Department, Wright State University, Dayton, Ohio 45435 \\ N. G. Paraskevopoulos and T. E. Anderson \\ Litton/Airtron, Electronic Materials Group, Morris Plains, New Jersey 07950 \\ R. L. Jones \\ Avionics Directorate, Wright Laboratory, WLAADM, Wright-Patterson Air Force Base, Ohio 45433
}

(Received 7 July 1997; accepted for publication 30 September 1997)

\begin{abstract}
A comprehensive characterization, including room temperature Hall effect, near infrared absorption, temperature dependent dark current and photocurrent (using $1.13 \mathrm{eV}$ light), normalized thermally stimulated current (NTSC), photoluminescence at $4.2 \mathrm{~K}$ in both near band edge and deep level regions, and selective pair photoluminescence (SPL) at $2 \mathrm{~K}$, has been carried out on undoped semi-insulating GaAs samples, cut from four wafers which were grown by the low pressure liquid encapsulated Czochralski technique and annealed by three different schedules: a $1100^{\circ} \mathrm{C}$ anneal with either fast or slow cooling, or a $1000^{\circ} \mathrm{C}$ standard anneal. The $1100{ }^{\circ} \mathrm{C}$ anneal clearly introduces higher concentrations of NTSC traps near 0.3 and $0.5 \mathrm{eV}$, a PL center at $0.8 \mathrm{eV}$, and acceptor centers, which are mainly due to the point defects and increase the resistivity. Slow cooling to some extent reduces all of these additional centers. The SPL measurements show changes in the relative intensities of $\mathrm{C}, \mathrm{Zn}$, and $\mathrm{Si}$ related emissions with changes in annealing conditions. (C) 1998 American Institute of Physics. [S0021-8979(98)07501-X]
\end{abstract}

\section{INTRODUCTION}

To improve the microscopic resistivity and photoluminescence uniformity and to reduce As precipitates in undoped semi-insulating (SI) GaAs wafers, and thus attain a better uniformity and higher yield of GaAs devices, various annealing processes have been investigated by many different laboratories. Typical annealing schedules include: (1) single step ingot annealing at $900-1000{ }^{\circ} \mathrm{C}$ for homogenizing EL2 defects, which are mainly agglomerated along dislocation cell walls; ${ }^{1}$ (2) multistep ingot annealing with, for example, two steps at $1100^{\circ} \mathrm{C}$ and $950^{\circ} \mathrm{C}$, respectively, or three steps at 1100,600 , and $900^{\circ} \mathrm{C}$, respectively, for reducing As precipitates and diminishing deep centers other than $\mathrm{EL} 2{ }^{2}$ and (3) multistep wafer annealing, first at $1100^{\circ} \mathrm{C}$ under As vapor pressure and then at $950^{\circ} \mathrm{C}$ in an open furnace, for further reduction of As precipitates. ${ }^{3}$ The cooling rate following the high-temperature annealing has been found to play a key role in the ultimate properties of annealed SI GaAs materials. For example, a semiconducting/ semi-insulating reversibility in undoped bulk GaAs was found to be controlled simply by the speed of the cooling rate after annealing at $950{ }^{\circ} \mathrm{C}$, which indicates that point defects play an important role in the electrical compensation. ${ }^{4}$ In the present study, a comprehensive characterization, which includes room-temperature Hall effect, near-infrared absorption (NIRA) for [EL2] determination, temperature dependent dark current and photocurrent (TDDC) and (TDPC), normalized thermally stimulated current (NTSC), photoluminescence (PL) in both the near band edge and deep level regions, and selective pair PL (SPL) measurements, was performed on undoped SI GaAs boules grown by the lowpressure liquid-encapsulated Czochralski (LP-LEC) technique. Before being sliced into wafers, the boules were subjected to high-temperature annealing at different temperatures and then were cooled at different rates. The particular annealing schedules included a $1100^{\circ} \mathrm{C}$ anneal with either fast or slow cooling and a $1000^{\circ} \mathrm{C}$ standard anneal. A significant variation of the electrical and optical properties in the annealed SI GaAs wafers was seen in nearly all of the measurements discussed above, and the results can be interpreted in terms of defect creation and changes in impurity incorporation.

\section{SAMPLES AND EXPERIMENTS}

A 4-in. LP-LEC SI GaAs boule was cut into three sections $(\mathrm{A}, \mathrm{B}$, and $\mathrm{C})$ and annealed in various ways, as shown in Fig. 1. Section A, near the seed, was annealed at $1100^{\circ} \mathrm{C}$ and cooled quickly (by pulling the ingot section from the furnace) and is labeled as $1100^{\circ} \mathrm{C}-\mathrm{Q}$; Section $\mathrm{B}$, in the middle of the boule, was also annealed at $1100^{\circ} \mathrm{C}$, but cooled slowly (by simply turning off the furnace) and is labeled as $1100^{\circ} \mathrm{C}-\mathrm{A}$; and Section $\mathrm{C}$, close to the tail, was annealed according to the Airtron $1000^{\circ} \mathrm{C}$ standard anneal and is labeled as $1000{ }^{\circ} \mathrm{C}-\mathrm{Std}$. One wafer from each of Sections $\mathrm{A}$ and $\mathrm{C}$ (wafer 016A and wafer 001C), and two wafers from Section B (wafers 001B and 018B, to check for ingot uniformity and measurement consistency) were studied. To check the lateral uniformity within a wafer, center, ring, and edge pieces $(6 \mathrm{~mm} \times 6 \mathrm{~mm}$ in size) from each wafer were measured and analyzed statistically. The metric for uniformity is the standard deviation (SD) of center, ring, and edge values divided by the mean, i.e., $\mathrm{SD} /$ mean, expressed as a percentage. Hall effect measurements were carried out at 296 $\mathrm{K}$ under vacuum and in the dark, using an automated highimpedance Hall effect apparatus with a magnetic-field strength of $4.8 \mathrm{kG}$. The neutral EL2 concentration was de- 


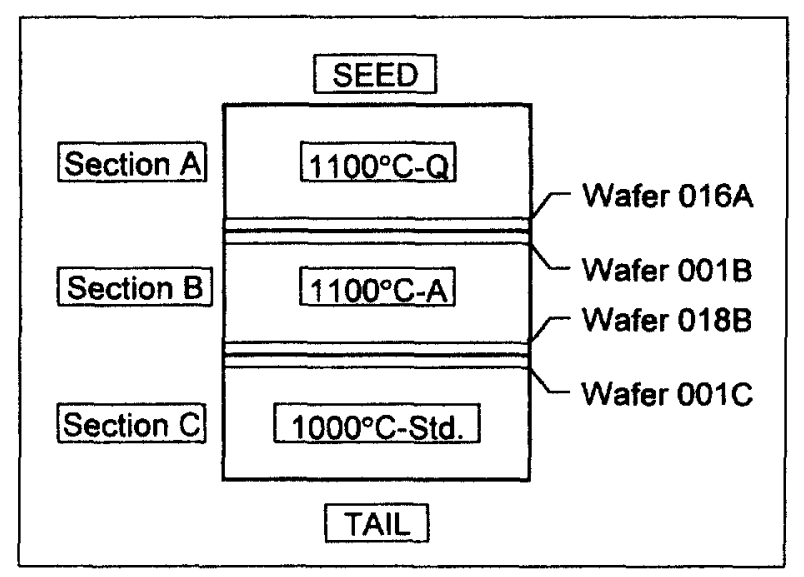

FIG. 1. Wafer positions and annealing conditions in a 3 in. LP-LEC GaAs boule.

termined by NIRA at $1.1 \mu \mathrm{m}$, using a Ge photodiode as a detector. Deep centers in SI GaAs, acting as traps, can be studied by TSC spectroscopy. In the TSC measurements, the sample was prepared with alloyed In contacts and then cooled to a low temperature near $80 \mathrm{~K}$, using a Bio-Rad DL4600 system, and finally illuminated with $1.45 \mathrm{eV}$ light, which mainly causes electron excitation from neutral EL2. After a period of excitation long enough to completely fill all the electron traps, the illumination was removed and the sample was linearly heated at a rate $\beta($ e.g., $0.3 \mathrm{~K} / \mathrm{s})$ in the dark, resulting in a TSC spectrum. A TSC peak in the temperature spectrum can be correlated with the energy level for a given trap by the formula $E_{T} / k T_{m}=\ln \left(T_{m}^{4} / \beta\right)+\ln (1.7$ $\times 10^{16} \sigma_{T} / E_{T}$ ), where $T_{m}$ is the peak temperature, $E_{T}$ and $\sigma_{T}$, the apparent energy level and capture cross section, respectively, and $k$, Boltzmann's constant. ${ }^{5}$ An Arrhenius plot of $\ln \left(T_{m}^{4} / \beta\right)$ vs $1 / T_{m}$ can be used to obtain $E_{T}$ and $\sigma_{T}$. To compare trap densities, a normalization procedure based on TDPC (using $1.13 \mathrm{eV}$ light) was employed; it can be shown that the normalized ratio $I_{\mathrm{TSC}} / I_{\mathrm{PC}}$ (called NTSC) is independent of mobility $\mu$, lifetime $\tau$, and geometric factors. ${ }^{6}$ Thus the NTSC spectrum gives a truer picture of the relative trap densities. To study the dominant deep center, which controls the dark conductivity in undoped SI GaAs, the TDDC was also measured. Photoluminescence measurements were made at $4.2 \mathrm{~K}$ using the $5145 \AA$ line of an Ar laser as an excitation source. The PL signals were detected by using a cooled Ge detector or a photomultiplier tube with $S-1$ response. The signals were analyzed by a $3 / 4-\mathrm{m}$ Spex spectrometer. SPL enables a definite identification of the residual shallow acceptors as well as a quantitative estimation of their relative concentrations. ${ }^{7}$ The measurement was performed at $2 \mathrm{~K}$ by using a $10 \mathrm{~mW}$ Ar ion laser pumped tunable dye laser. In this experiment the laser was tuned to $8200 \AA$. To search for the source of the acceptors, induced by high-temperature annealing, the residual impurities in four wafers were also analyzed by using glow discharge mass spectrometer (GDMS).

\section{RESULTS AND DISCUSSION}

The average electrical properties at $296 \mathrm{~K}$, i.e., resistivity $\rho$, mobility $\mu$, and electron concentration $n$, with their $\mathrm{SD} /$ mean values for four wafers, and the neutral, ionized, and total EL2 concentrations, i.e., [EL2 $\left.{ }^{0}\right],\left[\mathrm{EL}^{+}\right]$, and [EL2], respectively, in the central portion of each wafer, are given in Table I. We first note that all of the results for wafer 018B, including Hall, NIRA, TSC, DC, and PC data, are very close to those of wafer $001 \mathrm{~B}$, which thus confirms the good vertical uniformity along an ingot section and also the precision and reliability of our measurements. From Table I, we see that: (1) a $1100^{\circ} \mathrm{C}$ anneal (Sections $\mathrm{A}$ and $\mathrm{B}$ ), as compared to the standard $1000^{\circ} \mathrm{C}$ anneal (Section C), lowers the electron concentration and also the mobility; (2) fast cooling (after the $1100^{\circ} \mathrm{C}$ anneal) results in a much lower carrier concentration than does slow cooling; and (3) the wafer with $1000^{\circ} \mathrm{C}$-Std. annealing shows the best uniformity in terms of $\mathrm{SD} / \mathrm{mean}$ data for $\rho, \mu$, and $n$, while the wafers with $1100^{\circ} \mathrm{C}-\mathrm{Q}$ and $1100^{\circ} \mathrm{C}-\mathrm{A}$ annealings have slightly poorer uniformities. For conductive samples, the lower carrier concentration and mobility were earlier explained by an addition of acceptors, but with SI materials, homogeneity may also play a role in the mobility. However, a detailed electrical compensation analysis based on the electron concentration, neutral EL2, TDDC, and TDPC data, as shown below, indeed indicates an increase of acceptors in wafers annealed at $1100{ }^{\circ} \mathrm{C}$, especially those subjected to fast cooling. The question that we should answer concerns the possible sources of the acceptors.

TABLE 1. Average 296-K electrical properties and EL2 concentration.

\begin{tabular}{|c|c|c|c|c|c|c|c|c|}
\hline \multirow[b]{3}{*}{ Wafer } & \multirow[b]{3}{*}{ Anneal } & & \multirow{3}{*}{$\begin{array}{l}\text { Resistivity } \\
10^{7} \Omega \mathrm{cm}\end{array}$} & \multirow{3}{*}{$\begin{array}{l}\text { Mobility } \\
\mathrm{cm}^{2} / \mathrm{s} \mathrm{s}\end{array}$} & \multirow{3}{*}{$\begin{array}{c}\text { Electron } \\
\text { concentration } \\
10^{7} \mathrm{~cm}^{-3}\end{array}$} & {$\left[\mathrm{EL}_{2}{ }^{0}\right]$} & {$\left[\mathrm{EL} 2^{+}\right]^{\mathrm{a}}$} & [EL2] \\
\hline & & & & & & \multicolumn{3}{|c|}{ in central portion } \\
\hline & & & & & & \multicolumn{3}{|c|}{$10^{16} \mathrm{~cm}^{-3}$} \\
\hline \multirow[t]{2}{*}{$016 \mathrm{~A}$} & $1100^{\circ} \mathrm{C}-\mathrm{Q}$ & Mean & 12.83 & 6237 & 0.79 & 1.02 & 0.37 & 1.39 \\
\hline & & $\mathrm{SD} /$ mean & $11 \%$ & $3 \%$ & $8 \%$ & & & \\
\hline \multirow[t]{2}{*}{$001 \mathrm{~B}$} & $1100^{\circ} \mathrm{C}-\mathrm{A}$ & Mean & 4.68 & 6378 & 2.11 & 1.13 & 0.15 & 1.28 \\
\hline & & $\mathrm{SD} /$ mean & $11 \%$ & $2 \%$ & $10 \%$ & & & \\
\hline \multirow[t]{2}{*}{$018 \mathrm{~B}$} & $1100^{\circ} \mathrm{C}-\mathrm{A}$ & Mean & 4.45 & 6693 & 2.10 & 1.22 & 0.155 & 1.38 \\
\hline & & $\mathrm{SD} /$ mean & $7 \%$ & $4 \%$ & $4 \%$ & & & \\
\hline \multirow[t]{2}{*}{$001 \mathrm{C}$} & $1000^{\circ} \mathrm{C}$-Std & Mean & 2.08 & 7397 & 4.07 & 1.41 & 0.09 & 1.50 \\
\hline & & $\mathrm{SD} /$ mean & $6 \%$ & $1 \%$ & $6 \%$ & & & \\
\hline
\end{tabular}

$\left[\mathrm{EL}^{+}\right]$was estimated from Hall effect data, using $n=2.6 \times 10^{6}\left[\mathrm{EL}^{\mathrm{D}}\right]\left[\mathrm{EL} 2^{+}\right] \mathrm{cm}^{-3}$. 


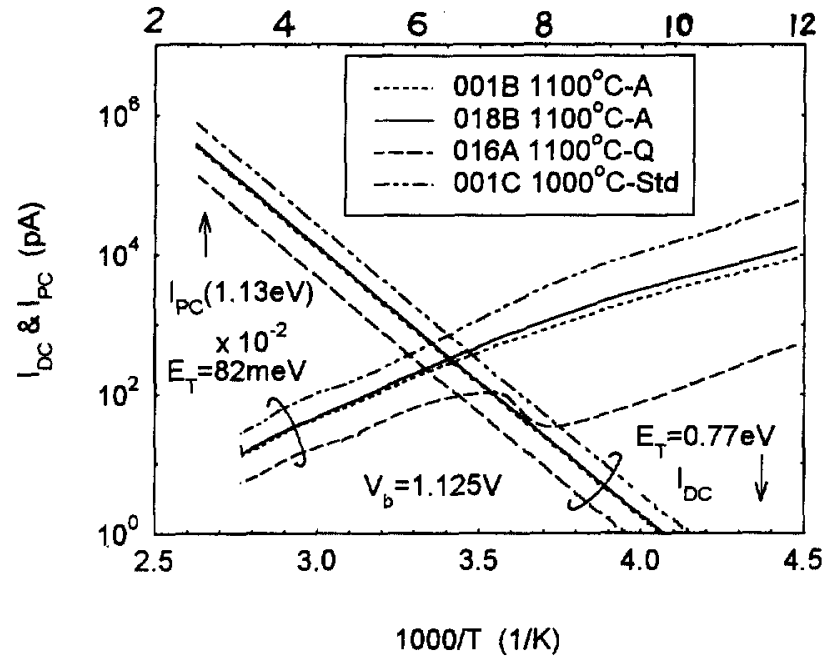

FIG. 2. Arrhenius plots of temperature dependent dark current and photocurrent (using $1.13 \mathrm{eV}$ light) for the center samples cut from four wafers.

Arrhenius plots of TDDC and TDPC, using $1.13 \mathrm{eV}$ light, for the center samples from four wafers, are presented in Fig. 2. Again, the results for the two samples of Section B are very close to each other. From Fig. 2, we also see that: (1) the activation energy for each DC plot is $0.77 \mathrm{eV}$, showing the control of EL2 in the dark conductivity; (2) the average activation energy for the PC plots at $T>140 \mathrm{~K}$ is about $82 \mathrm{meV}$, which is very close to the thermal activation energy of the electron capture cross section for EL2 $(66 \mathrm{meV}){ }^{8}$ if the temperature dependence of electron mobility is considered; (3) a clear IR quenching of PC at $T>140 \mathrm{~K}$ is found in sample $016 \mathrm{~A}\left(1100^{\circ} \mathrm{C}-\mathrm{Q}\right)$, which is due to the IR quenching of EL2 and is probably associated with the high concentration of ionized EL2, i.e., EL2 ${ }^{+}$; and (4) the PC's are proportional to the DC's at $T>200 \mathrm{~K}$. From observation 1, we infer that both carrier concentration and DC for all of the samples (assuming nearly equal mobilities) should be proportional to $N_{\mathrm{EL} 2} / N_{A}-1$, where $N_{\mathrm{EL} 2}$ is the total EL2 concentration and $N_{A}$, the net acceptor concentration. Because $N_{\mathrm{EL} 2}=N_{\mathrm{EL} 2}^{0}$ $+N_{\mathrm{EL} 2}{ }^{+}$and $N_{A}=N_{\mathrm{EL} 2}{ }^{+}$(since $n \ll N_{A}$ ), $n$ and DC are also proportional to $N_{\mathrm{EL} 2}^{0} / N_{\mathrm{EL} 2}{ }^{+}$. From the $n,\left[\mathrm{EL}^{\circ}{ }^{\circ}\right.$, and estimated $\left[\mathrm{EL}_{2}{ }^{+}\right.$], data in Table I, or the $300-\mathrm{K}$ DC data in Fig. 2 , it is easily found that as compared to sample 001C $\left(1000^{\circ} \mathrm{C}-\mathrm{Std}.\right)$, the net acceptor concentration in sample $016 \mathrm{~A}\left(1100^{\circ} \mathrm{C}-\mathrm{Q}\right)$ is increased by a factor of 4 and those in samples $001 \mathrm{~B}$ and $018 \mathrm{~B}\left(1100^{\circ} \mathrm{C}-\mathrm{A}\right)$, by a factor of 1.7 . The possible point defect nature for the high-temperature annealing induced acceptors will be discussed later. As stated in observation 4 , based on the data obtained from all the samples used in the study, a linear relationship between DC and $\mathrm{PC}$ at $300 \mathrm{~K}$ is found, as plotted in Fig. 3, which implies that the lifetime of electrons photoexcited from the EL2 ${ }^{\circ}$ center is inversely proportional to the $\mathrm{EL} 2^{+}$concentration, i.e., the higher the $\mathrm{EL} 2^{+}$or $N_{A}$ concentration, the lower the carrier lifetime. ${ }^{6}$ From the ratio of $\mathrm{PC} / \mathrm{DC}$ at $300 \mathrm{~K}$, which is about 2 for the light intensity of $3.3 \times 10^{14} \mathrm{phot} / \mathrm{cm}^{2} \mathrm{~s}$ used in this study, an electron capture cross section of

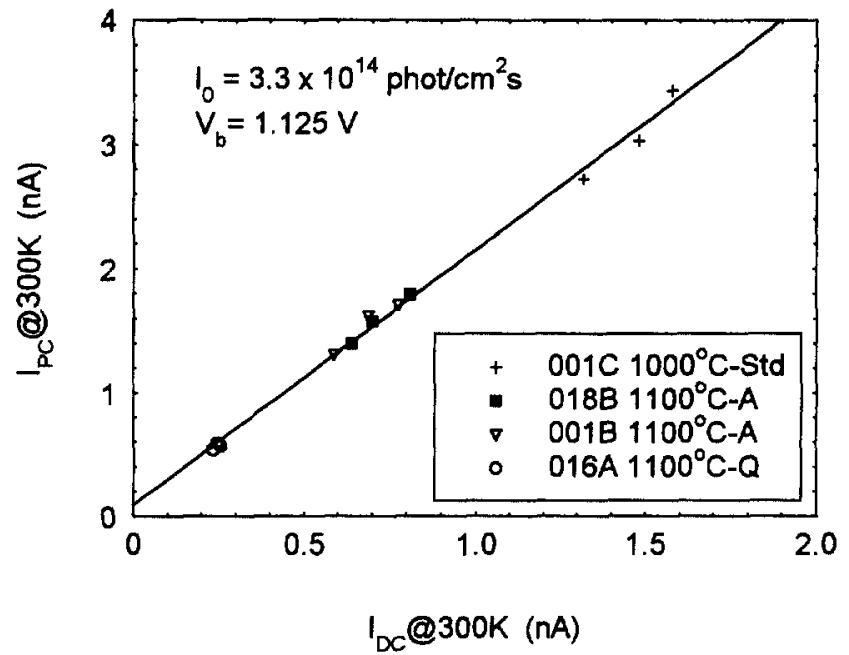

FIG. 3. Linear relationship between dark current and photocurrent at $300 \mathrm{~K}$ for 12 different samples cut from the center, ring, and edge of four wafers.

$1.4 \times 10^{-16} \mathrm{~cm}^{-2}$ at $300 \mathrm{~K}$ can be deduced for the EL2 ${ }^{+}$ center. $^{9}$

NTSC spectra for the four center samples are given in Fig. 4. From the figure, several significant effects of the annealing and cooling conditions can be observed: (1) the ratio of $T_{2}$ over $T_{3}$ is strongly affected, changing from greater than unity for sample $001 \mathrm{C}\left(1000^{\circ} \mathrm{C}-\mathrm{Std}\right.$. $)$ to less than unity for sample $016 \mathrm{~A}\left(1100^{\circ} \mathrm{C}-\mathrm{Q}\right)$; (2) $T_{5}$ is increased by the $1100^{\circ} \mathrm{C}-\mathrm{A}$ annealing, as compared to that of the $1000^{\circ} \mathrm{C}$ Std. annealing; and (3) more $T_{5}^{*}$ appears, and some $T_{5}$ is lost in sample $016 \mathrm{~A}\left(1100^{\circ} \mathrm{C}-\mathrm{Q}\right)$, resulting in an overlap of the two traps. Once again, the two samples from Section B show a very similar spectral structure. Our previous studies ${ }^{6,10,11}$ indicate that: (1) $T_{2}$, with $E_{T}=0.63 \mathrm{eV}$ and $\sigma_{T}=1.9$ $\times 10^{-13} \mathrm{~cm}^{2}$, is related to $A s_{\mathrm{Ga}}$, but is not identical to EL2 (also related to $\mathrm{As}_{\mathrm{Ga}}$ ) because of its different activation energy; (2) $T_{3}$, with $E_{T}=0.50 \mathrm{eV}$ and $\sigma_{T}=1.1 \times 10^{-13} \mathrm{~cm}^{2}$, might be associated with $V_{\mathrm{As}}$, most likely as a $V_{\mathrm{As}}$-related defect complex; and (3) $T_{5}$, with $E_{T}=0.35 \mathrm{eV}$ and $\sigma_{T}$

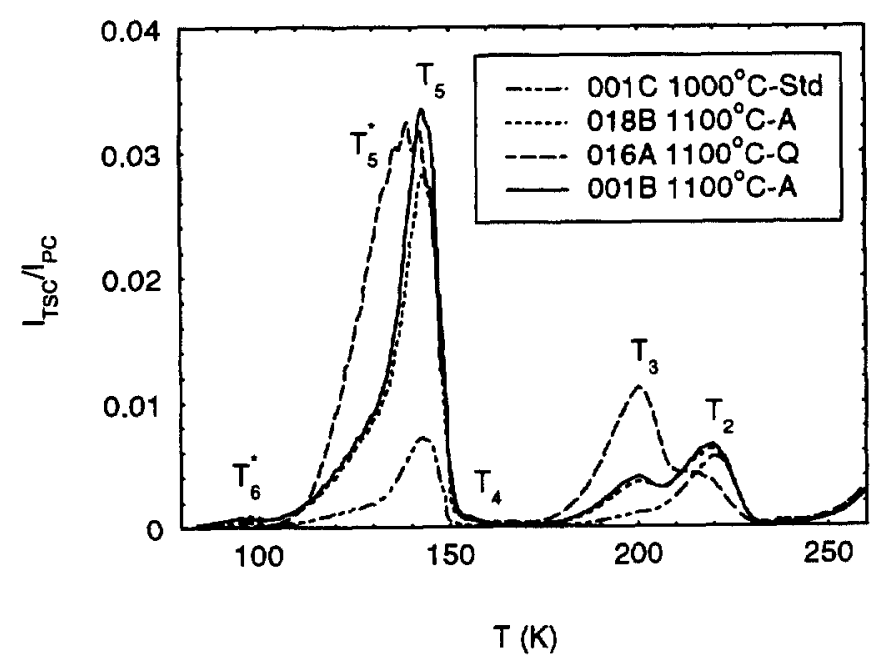

FIG. 4. Normalized TSC spectra for center samples cut from four wafers. 


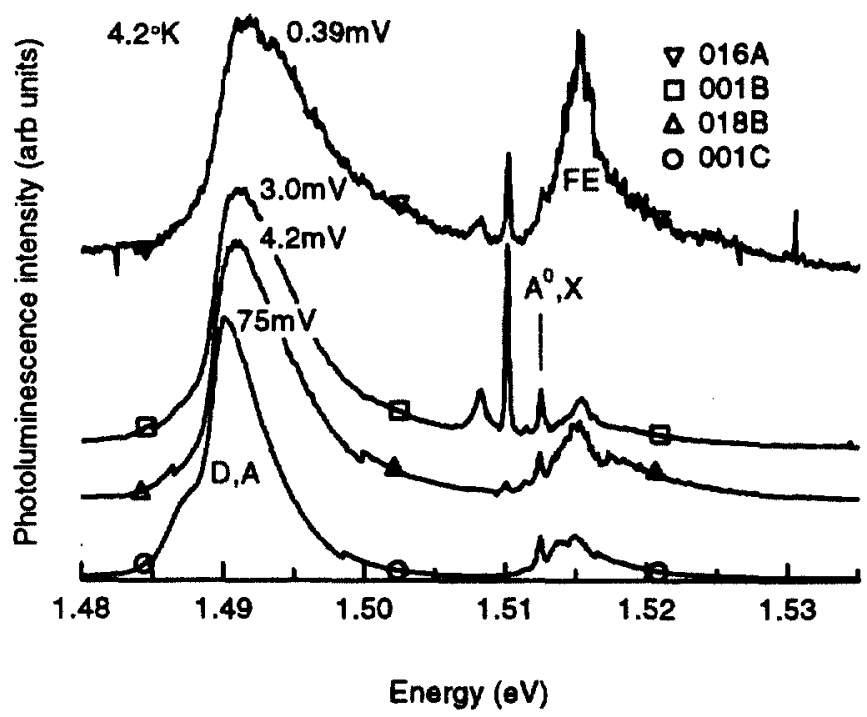

FIG. 5. Near-band-edge PL spectrum (4.2 K) of the center samples cut from four wafers (note each curve with its own scale).

$=1.9 \times 10^{-14} \mathrm{~cm}^{2}$, is very similar to EL6 and might be a complex involving both $A s_{\mathrm{Ga}}$ and $V_{\mathrm{As}}$ or $V_{\mathrm{Ga}}-V_{\mathrm{As}}$ and $\mathrm{As}_{i} \cdot{ }^{12,13}$ From an analysis of the density of $T_{2}$ in various undoped SI GaAs samples, ${ }^{6}$ we know that it is roughly proportional to $\left[\mathrm{EL} 2^{0}\right]$. In the present study, $\left[\mathrm{EL} 2^{0}\right]$ changes only about $30 \%$ among the four wafers. Thus, the main effect of the annealing at $1100{ }^{\circ} \mathrm{C}$, in comparison with the $1000{ }^{\circ} \mathrm{C}$ standard annealing, is to increase the $V_{\mathrm{As}}-$ and $V_{\mathrm{Ga}}$-related point defects.

The near band edge PL spectra from the center samples of the four wafers are shown in Fig. 5 (note each curve with its own scale). The transition for the decay of a free exciton $(\mathrm{FE})$, decay of an exciton bound to a neutral acceptor $\left(A^{0}, X\right)$, and annihilation of a donor electron and acceptor hole $(D, A)$ due to $\mathrm{C}_{\mathrm{As}}$ are shown. For the 001C sample $\left(1000^{\circ} \mathrm{C}\right.$-Std. $)$ the $(D, A)$ transition is at a slightly lower energy than in the other three $\left(1100^{\circ} \mathrm{C}\right.$ annealed) samples. Also, the $001 \mathrm{C}$ sample shows an additional transition at lower energy than the transition marked $(D, A)$ and is indicative of multiple acceptors. The presence of multiple acceptors in this sample will be further discussed in terms of selective pair PL. One of the striking differences is the magnitude of the PL signal. The intensities of the $(D, A)$ transition for $001 \mathrm{C}, 001 \mathrm{~B}, 018 \mathrm{~B}$, and $016 \mathrm{~A}$ are 75.0, 3.0, 4.2, and $0.39 \mathrm{mV}$, respectively, as shown in the Fig. 5. Thus, the intensity of the $001 \mathrm{C}\left(1000^{\circ} \mathrm{C}\right.$-Std. $)$ sample is 20 times greater than the average intensity of the $\left(1100^{\circ} \mathrm{C}-\mathrm{A}\right)$ samples, and the average intensity of the $\left(1100^{\circ} \mathrm{C}-\mathrm{A}\right)$ samples is 9.3 times higher than the $016 \mathrm{~A}\left(1100^{\circ} \mathrm{C}-\mathrm{Q}\right)$ intensity. On the low energy side of $\left(A^{0}, X\right), 001 \mathrm{~B}$ shows three distinct sharp transitions, 018B and 016A each show two, while $001 \mathrm{C}$ shows only the slightest hint of a transition. These sharp lines are attributed to bound exciton recombination at defect pairs, preferentially oriented parallel to one of the $\langle 110\rangle$ directions in the (001) growth plane. ${ }^{14}$ Figure 6 shows the PL spectra from the center samples of the four wafers for energies from above the band gap down to ap-

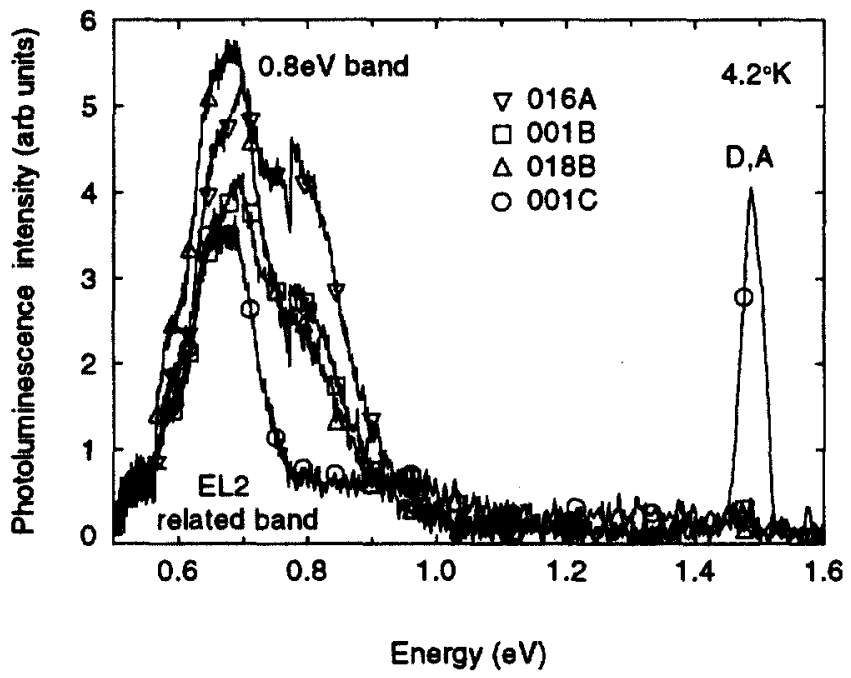

FIG. 6. Deep-level-region PL spectra $(4.2 \mathrm{~K})$ for the center samples cut from four wafers (note all curves with a same scale).

proximately a third of the band gap (note all curves have the same scale). The discontinuity at $0.775 \mathrm{eV}$ is caused by a filter change to maintain purity of the PL beam. The presence of the EL2-related $\mathrm{As}_{\mathrm{Ga}}$ defect is indicated by the two overlapping emission bands at 0.64 and $0.68 \mathrm{eV}$, respectively, attributed to conduction band to $\mathrm{As}_{\mathrm{Ga}}$, and $\mathrm{As}_{\mathrm{Ga}}$ to valence band recombinations. ${ }^{15}$ The $0.8 \mathrm{eV}$ emission band has been correlated with the EL6 center seen in DLTS. ${ }^{16}$ We believe the presence of this $0.8-\mathrm{eV}$ radiative recombination center effectively shunts the near band-gap $(D, A)$ transition and accounts for the factor of 20 decrease between the $001 \mathrm{C}$ $\left(1000^{\circ} \mathrm{C}-\mathrm{Std}.\right)$ intensity and the average of the $\left(1100^{\circ} \mathrm{C}-\mathrm{A}\right)$ intensities, and the further 9.3 decrease between the average of the $\left(1100^{\circ} \mathrm{C}-\mathrm{A}\right)$ intensities and the $016 \mathrm{~A}\left(1100^{\circ} \mathrm{C}-\mathrm{Q}\right)$ intensity. Control of the near-band-gap PL intensity by the recombination center responsible for the $0.8 \mathrm{eV}$ band has also been reported by Alt et al. ${ }^{17}$ in a room temperature PL mapping study of SI GaAs, followed by low-temperature PL measurements of the below band-gap region. A characteristic of the $\mathrm{Ga}$ antisite $\left(\mathrm{Ga}_{\mathrm{As}}\right)$ or $\mathrm{Ga}_{\mathrm{As}}-V_{\mathrm{Ga}}$ is an emission transition at $1.441 \mathrm{eV}$ (Ref. 18) or $1.45 \mathrm{eV}{ }^{4}$ However, none of the four samples in this study show the presence of the $\mathrm{Ga}_{\mathrm{As}}$ defect in their PL spectrum of this region (not shown).

Figure 7 presents a comparison of $2 \mathrm{~K}$ SPL spectra from wafers $016 \mathrm{~A}\left(1100^{\circ} \mathrm{C}-\mathrm{Q}\right)$, 001B $\left(1100^{\circ} \mathrm{C}-\mathrm{A}\right)$, and $001 \mathrm{C}$ ( $1000^{\circ} \mathrm{C}$-Std.). The spectrum from wafer 018B (not shown) is similar to that of wafer $001 \mathrm{~B}$. From the figure we see that: (1) four transitions due to $\mathrm{C}: 2 S_{3 / 2}, \mathrm{Zn}: 2 S_{3 / 2}, \mathrm{Zn}: 2 P_{5 / 2}$ $\left(\Gamma_{8}\right)$, and Si: $2 S_{3 / 2}$ can be identified in all three wafers; (2) unexpectedly, C: $2 S_{3 / 2}$ is not a dominant SPL emission in these wafers; and (3) the dominant SPL emission in the wafers with either $1100^{\circ} \mathrm{C}-\mathrm{Q}$ or $1100^{\circ} \mathrm{C}-\mathrm{A}$ annealing is from zinc $\left(\mathrm{Zn}_{\mathrm{Ga}}\right)$, while in the wafer with $1000^{\circ} \mathrm{C}$-Std. annealing, is from silicon $\left(\mathrm{Si}_{\mathrm{As}}\right)$. The change of dominant SPL emission from $\mathrm{Zn}_{\mathrm{Ga}}$ to $\mathrm{Si}_{\mathrm{As}}$ caused by the anneal condition implies that the incorporation of impurities, like $\mathrm{Zn}$ and $\mathrm{Si}$, depends on the availability of $\mathrm{Ga}$ and As vacancies, which might be closely related to the anneal temperatures and the cooling 


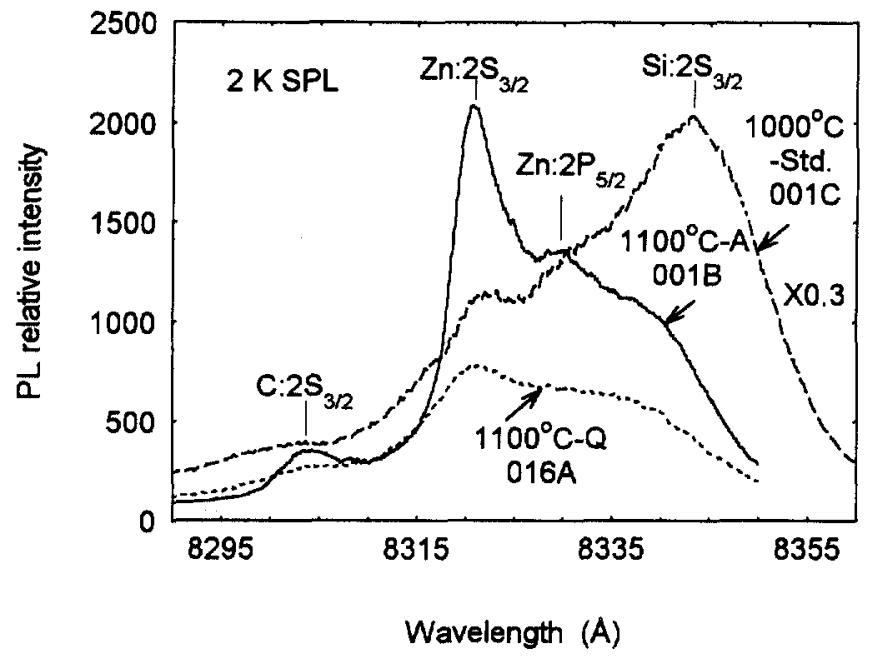

FIG. 7. $2 \mathrm{~K}$ selective pair PL spectra for the center samples cut from three wafers.

conditions. An M-shape distribution of $\mathrm{Zn}: 2 S_{3 / 2}$ across an as-grown SI GaAs wafer, as opposed to the usual W-shape distribution of EL2 or dislocation density, was reported by Koteles et al. ${ }^{7}$ Since EL2 is a $\mathrm{As}_{\mathrm{Ga}}$-related defect complex and the $\mathrm{Zn}$ acceptor occupies the $\mathrm{Ga}$ site, the $\mathrm{M}$ shape of $\mathrm{Zn}_{\mathrm{Ga}}$ versus the $\mathrm{W}$ shape of $\mathrm{As}_{\mathrm{Ga}}$ across an as-grown SI GaAs wafer means that a competition might exist between As and $\mathrm{Zn}$ for $V_{\mathrm{Ga}}$ sites or an anticorrelation between $\mathrm{As}_{\mathrm{Ga}}$ and $V_{\mathrm{Ga}}$ across the diameter of the wafer.

The introduction of acceptors into various GaAs materials, as a function of annealing and cooling conditions have been extensively studied in the past decade. ${ }^{4,19,20}$ The thermal conversion of SI GaAs from $n$ to $p$ type by hightemperature annealing at $1000-1200{ }^{\circ} \mathrm{C}$, either under As vapor pressure of $1 \mathrm{~atm}^{3}$ or in vacuum ${ }^{21}$ followed by fast cooling, has also been reported. Based on the thermodynamic equilibria of point defects, including antisites, vacancies, and interstitials of $\mathrm{Ga}$ and As, at the crystal growth temperature, and their interactions during the cooling process, many studies have concluded that intrinsic point defects, such as $\mathrm{Ga}_{\mathrm{As}}$ or $\mathrm{Ga}_{\mathrm{As}}-V_{\mathrm{Ga}}$, are responsible for the acceptor. However, to explain the $n$ - to $p$-type thermal conversion and the reduction of EL2 concentration by hightemperature annealing at $T>1150{ }^{\circ} \mathrm{C}$, an As-antisite breakdown mechanism has been also proposed; i.e., the $\mathrm{As}_{\mathrm{Ga}}$ breaks into $\mathrm{As}_{i}$ and $V_{\mathrm{Ga}},{ }^{21}$ and the latter can be a multiply charged deep acceptor $\left(E_{v}+0.52 \mathrm{eV}\right) .{ }^{22}$ In the present study, the near band edge PL spectra reveal an absence of $\mathrm{Ga}_{\mathrm{As}}$-related defects, possible candidates for the acceptors, in all four wafers, while the SPL spectra show a more dominating $\mathrm{Zn}: 2 S_{3 / 2}$ transition due to $\mathrm{Zn}_{\mathrm{Ga}}$ in the wafer after the $1100^{\circ} \mathrm{C}-\mathrm{Q}$ annealing. The results imply that in the wafer with $1100^{\circ} \mathrm{C}-\mathrm{Q}$ annealing there exist more $V_{\mathrm{Ga}}$ sites, which assists the incorporation of $\mathrm{Zn}$ impurity, as compared to the wafer with $1000^{\circ} \mathrm{C}$-Std. annealing. GDMS results show that the dominant acceptor in the four wafers is carbon, with a maximum change of a factor of two in their atomic densities, and that the other two acceptors are silicon and zinc, but with much lower atomic densities. That is, the $\mathrm{Si}$ concentration

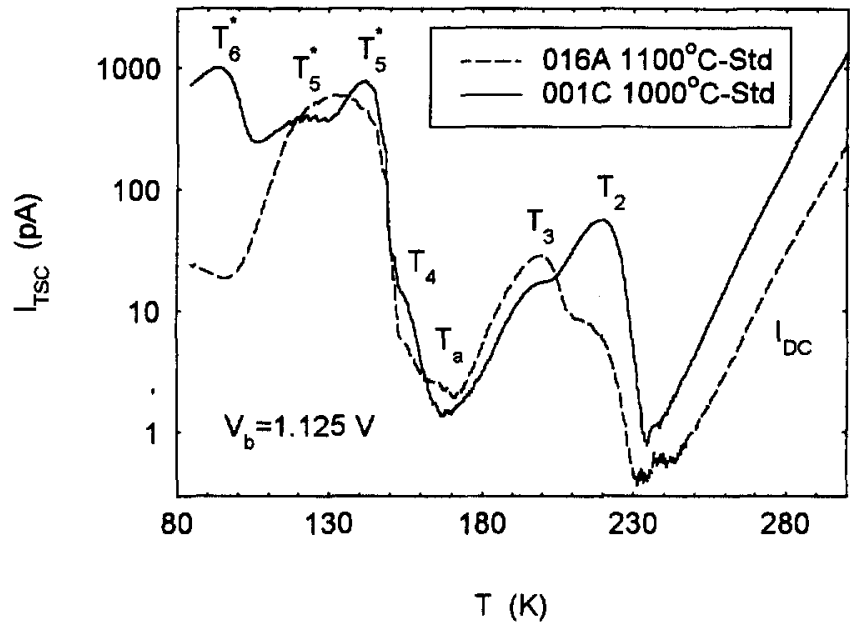

FIG. 8. Regular TSC spectra for samples $001 \mathrm{C}\left(1000^{\circ} \mathrm{C}-\mathrm{Std}\right)$ and $016 \mathrm{~A}$ $\left(1100^{\circ} \mathrm{C}-\mathrm{Q}\right)$.

varies less than a factor two, from $17 \mathrm{ppb}$ in sample $016 \mathrm{~A}$, to $9 \mathrm{ppb}$ in samples $001 \mathrm{~B}$ and $018 \mathrm{~B}$, and to $20 \mathrm{ppb}$ in sample $001 \mathrm{C}$. $\mathrm{Zn}$ varies from $22 \mathrm{ppb}$ in sample $016 \mathrm{~A}$, to $17 \mathrm{ppb}$ in sample 001B and $31 \mathrm{ppb}$ in sample 018B, and to $30 \mathrm{ppb}$ in sample 001C. These results cannot account for the variation of the acceptor concentration found in samples 016A and $001 \mathrm{C}$, which is estimated to be a factor of four. However, the variation in the PL intensity observed in the four samples can be correlated with the $0.8 \mathrm{eV}$ band and NTSC of $T_{5}$, both are considered to be related to a defect complex involving $V_{\mathrm{Ga}}, V_{\mathrm{As}}$, and $\mathrm{As}_{i}$. Therefore we infer that intrinsic point defects, such as $V_{\mathrm{Ga}}$, contribute to the introduction of acceptors into the wafer with $1100^{\circ} \mathrm{C}-\mathrm{Q}$ annealing. The other possible source of acceptors is the contaminant $\mathrm{Cu}$, entering the samples during high-temperature annealing. ${ }^{23}$ In the regular TSC spectra of samples $001 \mathrm{C}\left(100{ }^{\circ} \mathrm{C}\right.$-Std.) and 016A $\left(1100^{\circ} \mathrm{C}-\mathrm{Q}\right)$, as shown in Fig. 8, a TSC trap $\left(T_{a}\right.$ at $\left.170 \mathrm{~K}\right)$, which has an activation energy of $0.43 \mathrm{eV}$ and has been correlated with a $4.2 \mathrm{~K}$, Cu-related $\mathrm{PL}$ emission at $1.36 \mathrm{eV}$ and a Cu-related DLTS center at $E_{v}+0.42 \mathrm{eV}^{24-26}$ is indeed observed in the sample $016 \mathrm{~A}\left(1100^{\circ} \mathrm{C}-\mathrm{Q}\right)$.

To understand the semiconducting/semi-insulating reversibility of GaAs caused by a $950^{\circ} \mathrm{C}$ soak followed by slow or fast cooling, a tentative model was proposed by one of the present authors and his co-workers. ${ }^{4}$ In this model, a donor $(D)$ at $E_{c}-0.13 \mathrm{eV}$, observed in the semiconducting material, is attributed to $V_{\mathrm{As}}-\mathrm{As}_{\mathrm{Ga}}$, and an acceptor $(A)$ at $E_{v}+0.07 \mathrm{eV}$, observed in the semi-insulating material, is assigned to $V_{\mathrm{Ga}}-\mathrm{Ga}_{\mathrm{As}}$. A rapid cooldown (quench) freezes in significant amounts $\left(10^{15}-10^{16} \mathrm{~cm}^{-3}\right)$ of $V_{\mathrm{As}}-\mathrm{As}_{\mathrm{Ga}}$ and $V_{\mathrm{Ga}}-\mathrm{Ga}_{\mathrm{As}}$, and the latter complexes (plus other acceptors below midgap) dominate the former complexes (plus other donors above midgap) so that the deep donor EL2 can render the sample semi-insulating $([A]>[D]$ and $[E L 2]>[A]$ $-[D]$ ). A slow cooldown (anneal), on the other hand, permits the rather unstable $V_{\mathrm{Ga}}-\mathrm{Ga}_{\mathrm{As}}$ to breakup as $E_{F}$ rises, so that $[D]>[A]$ and the sample is conductive. However, it is also known that some donors shallower than EL2 can be created in significant amounts $\left(2 \times 10^{15} \mathrm{~cm}^{-3}\right)$ by heat treat- 
ment at $470{ }^{\circ} \mathrm{C}$ for a relatively long time, ${ }^{20}$ and these could also raise the Fermi level of the slowly cooled wafer, increasing the electron concentration. In the present study, we find a clear contrast in the electrical and optical properties between the wafers with $1100^{\circ} \mathrm{C}-\mathrm{Q}$ and $1100^{\circ} \mathrm{C}$-A anneals, but no resistivity conversion, as observed in the previously mentioned $950^{\circ} \mathrm{C}$ investigation. ${ }^{4}$ In comparison with $1100^{\circ} \mathrm{C}$-A annealing, $1100^{\circ} \mathrm{C}-\mathrm{Q}$ annealing causes: (1) a significant decrease of electron concentration, $\mathrm{DC}$, and $\mathrm{PC}$ due to an increase of acceptor concentration, which also results in a decrease of carrier lifetime since $N_{A}=\left[\mathrm{EL} 2^{+}\right]$; (2) an obvious increase of NTSC traps $T_{3}$ and $T_{5}^{*}$ (both of which are probably related to the As vacancy); (3) a clear increase of the $0.8 \mathrm{eV}$ band in the PL spectrum, which is believed to correlate with a DLTS center, EL6; ${ }^{16}$ and (4) more incorporation of carbon $\left(\mathrm{C}: 2 S_{3 / 2}\right)$ and zinc $\left[\mathrm{Zn}: 2 P_{5 / 2}\left(\Gamma_{8}\right)\right]$ impurities in the SPL spectrum. Basically, all these results can be explained by using the point defect model proposed in Ref. 4. In the $1100^{\circ} \mathrm{C}-\mathrm{Q}$ annealing, we infer that: (1) the $V_{\mathrm{Ga}}$-related defect centers dominate the $V_{\mathrm{As}}-\mathrm{As}_{\mathrm{Ga}}$ centers and contribute an excess of acceptors; and (2) the $V_{\mathrm{As}}-\mathrm{As}_{\mathrm{Ga}}$ or $V_{\mathrm{As}}-\mathrm{As}_{i}-V_{\mathrm{Ga}}$ complexes contribute deep donor centers, like $T_{3}$ and $T_{5}^{*}$ in NTSC and the $0.8 \mathrm{eV}$ band in PL. In the $1100^{\circ} \mathrm{C}$-A annealing, on the other hand, the point complexes mentioned above can be annihilated by interactions with $\mathrm{Ga}$ and As interstitials, resulting in a decrease of the point defect related acceptors and deep donors. Unlike the case for the $950^{\circ} \mathrm{C}$-A sample studied in Ref. 4 , the dominant deep center in the wafer with $1100^{\circ} \mathrm{C}$-A annealing is a $0.77 \mathrm{eV}$ center due to EL2, which means that the $V_{\mathrm{As}}-\mathrm{As}_{\mathrm{Ga}}$ complex at $E_{C}-0.13 \mathrm{eV}$, even if it has reformed during some slow cooling stage at $400-600{ }^{\circ} \mathrm{C}$, does not exist in a sufficient concentration to compensate the acceptors induced by hightemperature annealing at $1100^{\circ} \mathrm{C}$.

Although the high-temperature annealing followed by fast cooling produces higher-resistivity and lower-mobility SI GaAs material, the electrical and optical uniformities of the material are quite good. This technique should be explored further, especially by comparing the performance of GaAs devices and integrated circuits fabricated on the various materials.

\section{CONCLUSIONS}

The effects of high-temperature annealing at $1100^{\circ} \mathrm{C}$, with fast or slow cooling, on the electrical and optical properties of undoped LP-LEC SI-GaAs have been studied by Hall effect, NIRA, TDDC, TDPC, NTSC, PL, and SPL measurements. In comparison with the Airtron $1000^{\circ} \mathrm{C}$ standard annealing, the $1100^{\circ} \mathrm{C}$ anneal clearly introduces: (1) higher concentrations of NTSC traps, $T_{5}$ near $0.3 \mathrm{eV}$ and $T_{3}$ near $0.5 \mathrm{eV}$, both probably $V_{\mathrm{As}}$ or $V_{\mathrm{As}}-V_{\mathrm{Ga}}$ related; (2) higher intensities of the 4.2-K PL emission band at $0.8 \mathrm{eV}$ along with a significant decrease in the PL intensity of the $(D, A)$ transition, due to a decrease of carrier lifetime; and (3) higher concentrations of acceptor centers, dominated by point defects, like $V_{\mathrm{Ga}}$, rather than by shallow impurities, resulting in a significant increase of the resistivity. The slow cooling reduces all of these additional centers to some extent. The SPL measurements at $2 \mathrm{~K}$ show a clear change in the relative intensities of $\mathrm{C}_{\mathrm{As}}, \mathrm{Zn}_{\mathrm{Ga}}$, and $\mathrm{Si}_{\mathrm{As}}$ related emissions with changes in annealing conditions.

\section{ACKNOWLEDGMENTS}

We wish to thank T. Cooper and W. Rice for Hall effect and PL measurements, respectively. Z-Q.F. D.C.R., and D.C.L. were supported by U.S. Air Force Contract No. F33615-C-1619, and parts of the work were performed at the Avionics Directorate, Wright Laboratory, Wright-Patterson Air Force Base, $\mathrm{OH}$.

${ }^{1}$ R. Rumsby, I. Grant, M. R. Brozel, E. J. Foulkes, and R. M. Ware, in Semi-Insulating $I I I-V$ Materials, edited by D. C. Look and J. S. Blakemore (Shiva, Nantwich, 1984), p. 165.

${ }^{2}$ K. Kashiwa, Y. Otoki, M. Seki, S. Taharasako, and S. Okubo, Hitachi Cable Rev. 9, 55 (1990); Y. Otoki, M. Watanabe, T. Inada, and S. Kuma, J. Cryst. Growth 103, 85 (1990).

${ }^{3}$ M. Mori, G. Kano, T. Inoue, H. Shimakura, H. Yamamoto, and O. Oda, in Semi-Insulating III-V Materials, edited by A. G. Milnes and C. J. Miner (Adam Hilger, New York, 1990), p. 59.

${ }^{4}$ D. C. Look, P. W. Yu, W. M. Theis, W. Ford, G. Mathur, J. R. Sizelove, D. H. Lee, and S. S. Li, Appl. Phys. Lett. 49, 1083 (1986).

${ }^{5}$ D. C. Look, Semicond. Semimet. 19, 75 (1983).

${ }^{6} Z$-Q. Fang and D. C. Look, Inst. Phys. Conf. Ser. 149, 43 (1996).

${ }^{7}$ E. S. Koteles, J. Kafalas, S. Zemon, and P. Norris, Inst. Phys. Conf. Ser 83, 63 (1987).

${ }^{8}$ A. Mitonneau, A. Mircea, G. M. Martin, and D. Pons, Rev. Phys. Appl. 14, 853 (1979)

${ }^{9}$ D. C. Look and Z-Q. Fang, J. Appl. Phys. 80, 3590 (1996).

${ }^{10}$ Z-Q. Fang, D. C. Look, S. Kuisma, K. Saarinen, and P. Hautojarvi, in Proceedings of 9th Conference on Semiconducting and Insulating Materials. Toulouse, France, edited by C. Fontaine (IEEE, New York, 1996), p. 149.

${ }^{11}$ Z-Q. Fang, D. C. Look, H. Yamamoto, and H. Shimakura, Appl. Phys. Lett. 69, 3417 (1996).

${ }^{12}$ T. Wosinski, A. Makosat, and Z. Witczak, Semicond. Sci. Technol. 9, 2047 (1994).

${ }^{13}$ Z-Q. Fang, T. E. Schlesinger, and A. G. Milnes, J. Appl. Phys. 61, 5047 (1987).

${ }^{14}$ M. S. Skolnick, T. D. Harris, C. W. Tu, T. M. Brennan, and M. D. Sturge, Appl. Phys. Lett. 46, 427 (1885).

${ }^{15}$ M. Tajima, Jpn. J. Appl. Phys., Part 1 26, L1060 (1987).

${ }^{16} \mathrm{~S}$. Alaya, M. A. Zaidi, G. Marrakchi, H. Maaref, H. J. von Bardeleben, and J. C. Bourgoin, Mater. Res. Soc. Symp. Proc. 163, 163 (1990).

${ }^{17} \mathrm{H}$. Ch. Alt, M. Mullenbom, and G. Packeiser, in Semi-Insulating $11 \mathrm{I}-\mathrm{V}$ Materials, edited by A. G. Milnes and C. J. Miner (Adam Hilger, New York, 1990), p. 309.

${ }^{18}$ S. Alaya, H. Maaref, H. J. von Bardeleben, and J. C. Bourgoin, Appl. Phys. Lett. 56, 1877 (1990).

${ }^{19}$ T. Asom, J. M. Parsey, Jr., L. C. Kimerling, R. Sauer, and F. A. Thiel, Appl. Phys. Lett. 52, 1472 (1988).

${ }^{20}$ Y. Kitagawara, N. Noto, T. Takahashi, and T. Takenaka, Appl. Phys. Lett. 52, $221(1988)$

${ }^{21}$ N. Ohkubo, M. Shishikura, and S. Matsumoto, J. Appl. Phys. 73, 615 (1993).

${ }^{22} \mathrm{H}$. Xu and U. Lindefelt, Phys. Rev. B 41, 5979 (1990).

${ }^{23} \mathrm{~T}$. Hiramoto and T. Ikoma, in Semi-Insulating III-V Materials, Malmo, Sweden, edited by G. Grossmann and L. Ledebo (Adam Hilger, Bristol and Philadelphia, 1988), p. 337.

${ }^{24}$ Z-Q. Fang, D. C. Look, and R. L. Jones, J. Electron. Mater. 26, L29 (1997).

${ }^{25}$ Z. G. Wang, H. P. Gislason, and B. Monemar, J. Appl. Phys. 58, 230 (1985).

${ }^{26}$ A. Mitonneau, G. M. Martin, and A. Mircea, Electron. Lett. 13, 666 (1977). 